Mis au bénéfice, dès janvier 1977 , d'un congé d'une durée indéterminée par le Département politique fédéral, $M$. Pestalozzi, en plus de sa qualité de membre du CICR, sera également assistant spécial du président du CICR, M. Alexandre Hay, fonction qu'il occupera en permanence au siège du CICR à partir du $1^{\text {er }}$ février 1977.

Le CICR se félicite de cette nomination et de pouvoir bientôt bénéficier de la précieuse collaboration de M. Pestalozzi.

\title{
Marques de gratitude
}

Le 16 décembre eut lieu, au siège du CICR, une cérémonie au cours de laquelle le Comité international a manifesté sa gratitude à trois de ses collaborateurs.

A M. Jean-Pierre Maunoir et $M^{\text {me }}$ Rose Parmelin, le CICR a décerné sa médaille d'argent pour trente ans d'activité au service de l'institution; et M. Joseph Abramiec a reçu le plateau d'argent du CICR pour vingt années d'activité. C'est le président du CICR, M. A. Hay, qui leur remit ces marques de gratitude.

En son nom propre comme en celui de ses collègues, M. J.-P. Maunoir a remercié le CICR pour la distinction dont ils étaient l'objet.

\section{Décès de $M^{\mathrm{Il}} \mathbf{P}$. Y. Tombet, directeur au CICR}

Le Comité international a appris avec un profond regret le décès, le 15 décembre, après une courte maladie, de Mule Paulette Y. Tombet, membre de la direction du CICR et directrice de l'Agence centrale de Recherches.

M1le Tombet était entrée au service du CICR en décembre 1940, comme employée du service français à l'Agence centrale des Prisonniers de guerre. En 1947, elle devint chef du Secrétariat du service français puis en 1951, chef du service hongrois. En 1957, elle fut promue chefadjoint à la direction de l'Agence. Tout en gardant ces fonctions, elle assura dès 1964 le Secrétariat de la Présidence du CICR et prit également la direction du service du Protocole. En 1966, elle fut nommée directrice de l'Agence centrale de Recherches et devint en 1973 membre de la direction du CICR. 
C'est donc trente-six ans de sa vie presque jour pour jour, que Paulette Tombet consacra au CICR, donnant à tous un exemple d'intelligence pratique, de dévouement constant et de travail inlassable, accompli avec un total oubli de soi.

Le Comité international lui en demeure profondément reconnaissant et les amis nombreux qu'elle avait garderont un souvenir fidele de son attachante personnalité.

Lors de la cérémonie funèbre, M. M. A. Naville, membre et ancien président du CICR, lui a rendu un dernier hommage:

Celle qui vient de nous quitter nous avait habitué à sa présence et à son accueil. Nous partions, nous revenions, elle restait là, fidèle au poste, toujours prête... Elle voyait tous les jours défiler sous ses yeux des centaines de milliers de noms, et elle comprenait que derrière chacune des fiches se jouait une déchirante tragédie humaine et familiale. Directrice de l'Agence, poste si lourd de responsabilités, elle devait l'occuper avec un grand courage, mue par son esprit de dévouement et ce besoin qu'elle avait de se consacrer à une cuvre toujours renouvelée et qui la renouvelait elle-même: la générosité du cœur ne lui demandait jamais d'effort. 